\title{
Quality Gifts:
}

\section{Issues in understanding quality volunteering in human services}

Rosemary Leonard, Jenny Onyx and Helen Hayward-Brown

\begin{abstract}
Organisations providing human services are under increasing pressure to demonstrate quality from a range of sources such as new legislation and new requirements for government funding. Four dimensions for examining quality, derived from program evaluation theory, illustrated some of the contradictions surrounding these expectations. The research used a qualitative and grounded approach to exploring clients', volunteers' and coordinators' notions of quality service. The clients' and volunteers' perceptions of quality were highly experiential, related to the specific context and focussed on strong trusting personal relationships. Clients were also very conscious of their lack of power. Coordinators used a combination of approaches to try to satisfy the demands of clients, volunteers and bureaucracy.
\end{abstract}

Rosemary Leonard, Jenny Onyx and Helen Hayward-Brown

Rosemary Leonard is an Associate Professor in Social Science from the Research Centre for Social Justice and Social Change at the University of Western Sydney. She is on the Management Committee of Australian \& New Zealand Third Sector Research.

Jenny Onyx is Professor of Community Management at University of Technology Sydney. She is Director of the Centre for Australian
Community Organisations and their Management (CACOM) and on the Board of the International Society for Third Sector Research.

Dr Helen Hayward-Brown is a sociologist and anthropologist and a research fellow at the Research Centre for Social Justice and Social Change at the University of Western Sydney. 
As third-sector organisations delivering human services become more dependent on government funding, they are becoming increasingly subject to government demands for accountability (McDonald, 1999; Mulgan, 2001). Such demands can effectively define "quality of service" but not necessarily in a way that service providers and clients agree with. Indeed the wide debates around issues of quality have often highlighted differences between the perspectives of government and organisations engaged in service provision.

Since the 1970s the focus has been on the evaluation of quality outcomes. According to Gibson (1998), the governments' position is that it is "commonsense" to set up accountability and performance monitoring frameworks against desired outcomes. However defining those desired outcomes is particularly difficult in human services. For example, services in aging and disability often cannot be expected to provide an improvement in the life circumstances of the recipients, who nevertheless are very pleased and comforted by receiving help. Problems include the differentiation of process from outcome, the direction of causality, and difficulties in data collection. The perceived objectives of a program may also influence satisfaction with outcomes. For example the outcome of the small amounts of financial assistance given to those in hardship will be viewed more positively if such handouts are viewed as a temporary measure than if they are seen as necessary supplements to inadequate government benefits (Wearing, 1998). However despite the recognition of difficulties, the "commonsense" of government is prevailing and accountability requirements in terms of measurable outcomes are increasing. For example the Australian government Department of Health (2004) lists lengthy and exacting requirements for the accreditation of a nursing home or hostel. Ironically, Postle (2002) found that increasing demands for paperwork by government left managers less time for building relationships hence there were increased tensions and staff problems which negatively affect quality of service.

Debates about quality have also related to the desirability of adopting strategies from the for-profit sector such as benchmarking and quality management. For example, Freeman (2001) recommends a best practice model from the for-profit sector for the management of volunteers. The model focuses on Enablers, including management responsibilities, policies and procedures, documentation, continuous improvement, and Operations including recruitment, training workplace conditions, deployment monitoring and review. These lead to measurable Results. It does not engage with the difficult issues such as difficulties in identifying what constitures a good result, or different priorities among stakeholders. Even in the for-profit sector where results are more easily measurable Quality Management approaches are contested. Although supporters argue that QM methods empower employees in their immediate work context, they have also been associated with increased control by management and intensification of work practices (Rees, 2001). Certainly such managerialism seems incompatible with the coordination style preferred by volunteers in human services (Leonard, Onyx \& Hayward-Brown, 2004).

The present analysis takes a step back from the current debates in the sector to examine the key issues in defining quality as described in evaluation theory, the field within the social sciences where the definition and measurement of quality has been most widely discussed. These issues are used as a frame for examining how quality has been understood in human services. Further, they serve as a way of examining the data in the present study on clients', volunteers' and coordinators' perceptions of quality. 
Four dimensions for the identification of quality can be identified from evaluation theory.

1 The Fixed.Contextual dimension. The Fixed approach is best illustrated by early approaches to evaluation using the physical sciences as their point of reference, for which it was assumed that the function of things gave a clear indication of how quality should be understood (eg clocks need to be accurate) The focus was the measurement of quality with highly technical debates about educational and psychological testing, which continue to the present time (Cliff \& Keats, 2003). In the 1930s, however, Tyler (Smith \& Tyler, 1942) introduced objectives-based evaluation, still a very current form of evaluation. This approach assumes that quality can be assessed by measuring ourcomes against stated prior objectives. Because quality is defined at the point at which the objectives are set, it is open to contextual variations.

2. The Expert-Experiential dimension. The majority of approaches to evaluation assume that quality will be defined and measured by an expert. The debate has mainly been about the type of expert required. For example, by the 1960s there was recognition that objectives also needed to be open to evaluation and it became the evaluator's role to assess both objectives and outcomes. Quality, therefore, was now defined by the evaluator, a professional expert external to a program. For example, in the Connoisseurship Model of evaluation (Eisner, 1979), evaluators, like connoisseurs of the fine arts, use their knowledge, skill and taste to identify quality. However in the 1980s, Guba and Lincoln (1986) had introduced "Fourth Generation Evaluation" in which they argued for equal standing for all stakeholders in the evaluation of both program objectives and outcomes thus giving equal status to the experiential knowledge of clients and staff.

3. The Single-Multiple dimension. When quality is seen as fixed, set by the objectives of a program or defined by an expert, there is only a single concept of quality for any evaluation. In contrast Fourth Generation Evaluation allows for multiple definitions, as each stakeholder group may have their own ideas about a quality service. For example, funding agencies, managers, staff, volunteers and clients may have varying ideas about what counts as quality. The possibility of multiple definitions requires a radically different approach in which negotiation becomes as important as judgement and measurement.

4. The Power dimension. Emancipatory approaches not only recognise the many stakeholders but also their differences in power (eg Wadsworth, 1997). The least powerful are usually the "critical reference group," the people who are receiving the program or services. Emancipatory approaches argue that although all stakeholders need to be considered, it is the critical reference group whose opinions must be given precedence.

Organisations providing human services are under increasing pressure from a range of sources to demonstrate quality. These sources include new legislation (eg public health, occupational health and safety, child protection, corporate reporting) new requirements for government funding, which include a combination of bureaucratic and market model expectations, internal pressures from their organisational model (eg charity or community management). However, as shown in Table $L$, the assumptions about quality for each of these expectations are likely to differ widely. 
Table 1. Dimensions of the definitions of quality for each of the pressures on humanservice delivery

\begin{tabular}{|l|l|l|l|l}
\hline & Fixed/Contextual & $\begin{array}{l}\text { Expert/ } \\
\text { Experiential }\end{array}$ & Single/ Multiple & Emancipatory \\
\hline $\begin{array}{l}\text { Legislation \& } \\
\text { Bureaucratic funding }\end{array}$ & Fixed & Expert & Single & All treated equally \\
\hline Market model funding & Contextual & Experiential & Multiple & No \\
\hline Charity model & Fixed & Expert & Single & No \\
\hline $\begin{array}{l}\text { Community } \\
\text { management model }\end{array}$ & Contextual & Experiential & Multiple & Yes \\
\hline
\end{tabular}

Human service providers are affected by government pressures for quality through legislation and through their funding contracts. Governmental approaches to quality have traditionally assumed fixed, single, expertly defined levels of quality can be clearly identified and apply across all sectors of society. Universal standards are developed, often in response to severe abuses, and the focus is on protecting the public from harmful practices.

Legislation, (including sanctions), is used to try to enforce the standards. So this approach emphasises quality as singular and fixed and does not recognise the different power contexts of people affected by the legislation. Indeed the universality of standards creates equity, which is seen as the strength of this approach as those with power are still subject to the law. Funding contracts can also be used to try to enforce those receiving grants to maintain adequate standards of service for clients and deter organisations from judging people's entitlements according to their own idiosyncratic values. Governments seem to see third sector community service providers as extensions of government (Lyons, 2001) and therefore subject to the same bureaucracy. From Weber (1978) bureaucracy can be understood as a form of control through rationality, which involves professionalism, expertise, impersonality, specialisation, hierarchy and rules. Thus in a bureaucratic view, quality is defined by experts, fixed and singular with the intention to control rather than empower.

A market approach to quality assumes that free market competition will naturally lead to increases in quality. Customers indicate their perception of quality by the amount they are prepared to pay for a product. Effectively quality becomes defined tautologically as whatever market competition produces. In terms of the four dimensions, this approach establishes quality from the choices of naïve users (ie experiential assessment, possibly informed by expert knowledge). There is not necessarily any objective standard. Multiple positions can co-exist through diverse products. The difference in positional power among customers is not seen as relevant because it is natural that some customers will have more choice than others. The power of the producer to influence customer perceptions through advertising and other devices is also seen as normal and desirable.

Over the last two decades many governments, including British and Australian, have adopted 'the New Public Management' (George and Wilding, 2002) believing that a market orientation will provide better services for less cost. They have therefore artificially created a market model for human service delivery (McDonald and Marston, 2002) with competition amongst providers and the State purchasing services on behalf of the client. 
However governments have not abandoned their orientation towards accountability, and fairly rigid procedures.

The traditional charity model has been and continues to be a major model for the provision of most human services, with many organisations being associated with the Church. Indeed of the sixteen largest multi-service non-profit providers, eleven were church sponsored and several others had religious motivation but not a direct affiliation. Ten of the eighteen largest aged care providers are also church sponsored (Lyons, 2001). In the traditional charity model, organisations are managed by boards of trustees, who are usually respectable citizens such as clergymen, professionals and benefactors. All programs are increasingly influenced by government regulation and scrutiny. Nevertheless, in practice, the trustees are effectively only answerable to each other (Mulgan, 2001). Quality, as defined by such boards, is likely to be informed by religious values, fixed and singular, assuming the right of the board to make such judgements, however, any particular board may take a pluralist or emancipatory approach.

Over the last 30 years, many organisations delivering human services have developed under the community management model, which has valued responsiveness to local needs, flexibility and local input (Darcy, 2002). Management committees committed to this model may, therefore, assess quality in terms of local context rather than universals. Those concerned with community development or having a particular concern with the emancipation of minorities are also likely to be conscious of issues of power in the definition of quality, recognizing the values of the critical reference group as having priority. Indeed under this model, the management committee should include representatives of service users. The model supports diversity among organisations in their values and programs. Under this model, organisations may experience pressure to be responsive to clients and local community needs.

Table 1 suggests that organisations providing human services under the community management model will have a mismatch with definitions of quality from bureaucratic funders. Although dimensions for the charity model match those for bureaucracy, there are likely to be differences in content as they appeal to different experts to identify the single, fixed notion of quality. Further the mixture of a market approach with a bureaucratic approach adds another layer of complexity. Given the potentially conflicting pressures for quality experienced by human service providers, the question arises of how those within the organisation handle those pressures and ultimately whether the clients, as the critical reference group, feel they are receiving a quality service.

The present research addresses the issue of quality from the perspectives of the clients, volunteers and their coordinators in the "Women Volunteers in Human Services" study. Previous analyses found that the volunteers wanted to make a quality contribution to their community. Leonard and Hayward-Brown (2002) identified 'Efficacy through Caring', 'Social Connection', and 'Recognition (versus Exploitation)' as the dominant themes, which seemed to represent how the women constructed their voluntary work. The metaphor of the gift appeared to encapsulate much of the women's perspective. It was also found (Onyx, et al, 2001) that volunteers and some coordinators had strong objections to many of the regulations recently imposed by governments, which they felt impeded rather than facilitated quality service. These new requirements appeared to the participants as subjecting them to the constant threat of litigation and curtailed their main sources of 
fund-raising. Further, as volunteers generally regard themselves as 'upstanding members of the community', there was a sense of offence at such legislative measures. In rural communities the subsequent loss of voluntary labour was affecting service delivery and managernent. A number of services had been closed due to inability to comply with precise and costly regulations, leaving clients at far greater risk. Thus it can be inferred that volunteers and some coordinators are not committed to bureaucratic models of quality. Clients' views about quality may be different again.

The present analysis uses a qualitative and grounded approach to exploring clients', volunteers' and coordinators' notions of quality in a service provided by volunteers. Simply by asking a variety of non-experts about quality, these research questions imply certain possibilities about its nature. It suggests that experiential knowledge can make a contribution and that there may not be a single objective notion, so that differently positioned stakeholders may have different opinions.

\section{Method}

Because the aim of the research was a deeper understanding of the clients, volunteers' and coordinators' views of service delivery, the research was conducted within a qualitative paradigm, employing individual and focus group interviews. In all the interviews, issues of quality were specifically pursued but also emerged from the discussion of other topics. It should be emphasised that the sample was small and purposive, not random. The purpose of the study was not to generalize but to explore the dynamics of volunteers' work in relationship to their organizations. Such exploratory research requires qualitative analysis of in depth discussion for a limited number of people. It is likely that the social mechanisms so identified may well have broad applicability, though this will have to be established in further research.

Participants. The research involved 10 focus groups and 20 individual interviews with women volunteers in human services, 20 individual interviews with clients, and 21 individual interviews with coordinators. Roughly half the participants came from an urban and half from a rural region of NSW, Australia.

Clients. Clients' ages ranged from 25 to 89 years. Sixteen were fernale and four were male. Five were from a non-English speaking background. Twelve did not complete their leaving certificate or HSC. Half of the clients were married and half were single (never married, divorced or widowed). The services they received were counselling, support after major surgery, support with a new baby and ongoing help in a day-care disability cottage, drug centre, parent support group, hospice and senior citizen's group.

Volunteers. The 120 women who attended the focus groups ranged in age from teens to eighties (Mean $=57$ years). A third of the urban volunteers but only $4 \%$ of the rural volunteers came from a non-English speaking background. The 20 volunteers, who were individually interviewed, ranged in age from 20 to 78 years ( $M e a n=53$ years). Only two came from a non-English speaking background. On average the volunteers worked approximately nine hours per week.

Coordinators. The 21 coordinators ranged in age from 28 to 75 years (Mean $=49.6$ years). Three were male. Five were unpaid. Only one was from a non-English speaking background. 
The volunteers and co-ordinators worked for organisations which provided a range of human services in palliative care, home maintenance, family support, disability, cancer support, migrant education, day care for frail aged and drug abuse, migrant support, prisoner welfare, youth services, health services and auxiliaries, school activities, respite care, country women's associations and breast cancer support.

Participants were recruited through newspaper advertisements, telephone canvassing through community handbooks, and organisational networks.

\section{Procedure}

Focus Groups - Each focus group followed the same format, with the same facilitator, and one other member of the research team. A standard set of questions and accompanying prompts was adopted in each case. The topics most relevant to the present analysis were: relationships to clients, perceived outcomes of volunteering, how organisations should work with volunteers.

Individual interviews with clients - The interview topics most relevant to the present analysis were: their relationship with the volunteers, and quality of service, areas of satisfaction or dissatisfaction, making complaints, consultation about their service.

Individual interviews with volunteers The interviews were semi-structured with topics similar to those for the focus groups with further emphasis on support, training, coordination, supervision, quality service for volunteers, and complaints procedures for clients.

Individual interviews with coordinators -The interview topics relevant to the present analysis were: training and keeping volunteers up-to-date, contact and feedback; dealing with inappropriate volunteer behaviour, recent legislation, complaints by clients, quality control

Focus group and individual interviews for coordinators and volunteers ran for two hours. Clients did not speak for so long, usually one hour. Individual interviews were held at a time and place suitable to them (Most coordinators chose their office, clients chose their home). Discussion was audio-taped and transcribed.

Analysis. A grounded approach was taken to the data analysis with codes being developed as the data is interrogated. N"VIVO was used to assist the process of documentation.

\section{Results}

The results present separately the clients, volunteers and coordinators' approaches to quality. Attitudes to regulation published previously (Onyx, Leonard \& Hayward-Brown, 2001) will not be repeated.

\section{The clients' view of quality}

By far the most salient theme to emerge from the client interviews was the importance of emotional safery in the service provision. Emotional safery involved being able to talk openly without fearing a judgemental response, or being reported to the authorities. For example a drug user could admit he had relapsed; mothers could admit they were less than perfect; a person with a disability did not feel she always had to be independent as possible; 
women from different cultural backgrounds could relax knowing they would not face prejudice. It involved being able to make requests without fear of being dismissed as a nuisance and being able to make complaints without fear of losing the service.

It was important for clients to feel that volunteers had the time to talk to them. They used the following language to describe the support offered by volunteers: 'sounding board'; 'you can go to them with problems'; 'a shoulder to cry on'; 'they comfort us'; 'if you have something on your mind' and 'the need for cuddles'. It is clearly important to clients that space is provided for this emotional support - time to talk and air their worries. Although there were generally very strong levels of trust shown by clients, some clients had concerns about confidentiality. One disabled client referred to them as 'gas-bags'.

Common experiences between volunteer and client were seen as a source of safety. For example, parents appreciated that the volunteers were also mothers themselves, and therefore understood them. Another client related well to volunteers who had army connections, because her husband had been in the army.

Clients valued continuity and stability. Change was only accepted if it was understood and seen to be reasonable. If there is to be change, clients appreciated being asked for feedback. One client commented on orhers who had left:

- they just could not get used to the idea at the time that things were going to change and move on. This is the good thing about here, you get your confidence dealt with, withour you realising it and you can cope with change in the structure and regularity. (SW Sydney)

The issue of loneliness and isolation seemed very strong for nearly all the clients. The elderly, disabled, and young mothers all felt this need for human interaction. As one young mother stated,

Isolation is a cancer - it niggles away at everything, so you become less confident. (SW Sydney)

In contrast, a safe environment with connections to others in the community could provide the opportunity to build their self-esteem and confidence. This seemed to particularly be the case in the context of small groups and one to one contact.

Most clients referred to the caring behaviour of volunteers, which they seemed to appreciate very much. Linked to this caring behaviour were some very strong feelings about their close connection to the volunteer. The volunteer was referred to as being 'like a friend' or even 'like family'.

Clients spoke about their physical needs in a matter of fact manner, but they were clearly pleased to have these needs met. These needs included, looking after children; delivery of meals; serving of refreshments, help with craft activities, help with some toileting, nail care, scribe services, and provision of bus transport between venue and home. Most of the clients used volunteers as a means of connection with the wider community. In particular, cultural support, in terms of translation and integration into the community, was important in the urban centres where there were multicultural communities. Clients spoke enthusiastically about the fun and enjoyment in the programs they attended. Clients paid 
very strong attention to every detail of the physical support that they received. For example, one client spoke about her concern abour dirty tablecloths.

It would appear that structural and organisational concerns of volunteer services were of very low priority for clients. Some clients did comment on improved resources, and their increased enjoyment as a result. Clients were also grateful if organisations were able to offer extra support at difficult times.

In terms of their service from volunteers, clients appreciated flexibility in their availability. Clients were pleased when volunteers listened to them and learned about their needs. Volunteers who took the initiative, e.g. offering clients a drink without being asked, were seen to be superior to others. Some volunteers also went beyond their normal duties, for example, helping to organise a party at a client's home. Clients were aware of the volunteer's level of reliability and commitment, and also their 'fairness' in the treatment of each client.

Most clients reported being confident about making complaints, but others would only do so with other clients. At one day-cottage for the disabled, there was a complaints box and regular surveys. However, a volunteer from this organisation said that the clients rarely spoke up due to fears of losing the service or being seen to be ungrateful. Some Management Committees had client representatives and one client took advantage of this to voice her complaints, which were always addressed in the newsletter.

\section{Volunteers perspective}

Efficacy through caring is the phrase the sums up the dominant attitude to quality from the perspective of the volunteers. That is, they want to make a difference through their work but they do so in the context of a personal caring relationship. In the focus groups volunteers spoke at every opportunity about the joy of caring for their clients. These attitudes were more explicit for those working directly with clients individually or in small groups. Most of the volunteers saw their work as something 'very special,' a gift 'given from the heart'. They believe that they should be respected for what they do.

Clearly there was a mirroring of the needs of the clients for emotional support in the volunteers satisfaction with providing care. Like their clients, volunteers often likened their clients to friends or family. They also spoke about the importance of hugging and some volunteers said they would ignore instructions not to. Other volunteers restricted themselves to touching hands from a concern with professional boundaries.

Other similarities were on issues of confidentiality and increases in client confidence. Volunteers gained huge satisfaction from signs of increased confidence in their clients. Volunteers spoke at length about clients' increased confidence, such as joining in activities, gaining independence, or using their new English skills. It appeared from both the focus groups and individual interviews that volunteers and co-ordinators were very aware of confidentiality issues, but no doubt there are occasional lapses.

The organisational ability of their workplace was less important than the opportunity for caring relationships. Volunteers raised issues such as clear job descriptions, work that matched their ability, background information on clients and organisation, information on legislative procedures and responsibilities, training and orientation to the job; obtaining advice and support. However, these were not the major topics. Volunteers could handle a 
little disorganisation and were more concerned about "over-control," an excess of rules anc regulations especially if they felt it demeaned their contribution. Flexibility of work schedules was particularly important to them.

Training and general preparation for volunteering was a common theme of the discussion about 'What organisations should do'. However, it was essential that the training be seen b. the volunteers to be directly relevant and necessary. Training was resisted when it was a requirement of government regulations, but not seen as developing their skills as volunteers. Most had learnt specific skills for their area of volunteering eg office skills, use of technology, cosmetic care, counselling and tutoring skills. In several cases, volunteering led participants to seek out formal education.

Most volunteers also responded positively to co-ordinator monitoring and supervision, as long as it was not heavy handed. They did not like to feel 'over-scrutinised' and liked to keet their autonomy.

\section{Coordinators' Perspective on Quality}

Most co-ordinators in the individual interviews showed an extraordinary amount of concern for the welfare of their clients. Even when they were not being directly asked abou the clients, discussion very often returned to these issues as the bottom line'. They were conscious that the quality of service to clients was the important issue, above and beyond the concerns of volunteers.

Coordinators covered a wide range of issues in relation to their concern for clients. Most mentioned adherence to confidentiality codes. Three of the co-ordinators focused primarily on physical safery issues. Others spoke about protecting clients from volunteers who could "drive them mad", the complexities in using male volunteers when a woman is alone at home, and the problem of volunteers who are more concerned about getting their own needs met, rather than meeting the needs of the clients. A rural coordinator spoke specifically about the problems raised by the competitive model of funding. When a small group of volunteers is stretched trying to provide basic services, they have no time and energy for the purting in an adequate submission for the extra resources they need for their clients.

They have not got the time to do the research. ... You have got no hope!

The first step was the selection of appropriate volunteers. Many of the co-ordinators spoke about the interview or training process as a means of 'weeding out' inappropriate volunteers. Some referred to strategies such as 'having a chat', making 'assessments' the use of references, using individuals such as ex-clients who are known to the organisation.

Formal police checks are required in some positions, which was a significant cost to those organisations and created problems when substitures had to be found for important services at short notice. So their concerns for clients related to finding appropriate volunteers but their methods varied greatly in the degree of formality.

Co-ordinators were generally positive about providing training for volunteers. For some organisations, training may occur in such an informal manner, that volunteers may not necessarily be aware that this is what they are undertaking. Other organisations provide very formal arenas for training, sometimes prompted by legislative requirements. Only three out of the twenty-one co-ordinators stated that they did not provide training 
programs. However those three coordinators did provide 'on the job' training. Most of the training involved orientation programs or specific job skills (e.g. cosmetic care, dealing with the elderly and dementia, assessment and referral skills). Some organisations included First Aid and $\mathrm{OH} \& \mathrm{~S}$ in their orientation, and most gave guidelines about their policies and procedures. Two co-ordinators referred to workshops on communication skills. Two had longer training (eg 10 weeks for palliative care). Co-ordinators generally reported positive responses to training from volunteers, although four commented about some difficulties. These problems were that training was only positively received if the volunteers can see the need for it; that only those few who were interested attended ongoing workshops; that there was some resistance to training, and that management committees did not feel that they needed training.

When volunteers commenced work, quality was monitored through role modelling by co-ordinator and other volunteers, a Buddy system, or starting off slowly with only a few tasks. Ongoing monitoring of volunteers occurred through coordinators' own informal observation of volunteer, observations by other staff, regular face to face meetings- both individual and group meetings, regular email contact, feedback from clients, self-assessment by the volunteer, and checking that jobs are completed.

Other concerns for clients related to strategies for improving quality of service. One co-ordinator spoke about purting herself in the place of the clients - thinking about what she would like if she were in their position. Another spoke about referring back to the goals of the program, to make sure that they were 'on track'. A few co-ordinators referred to the simple act of 'asking clients' about their needs. For one co-ordinator, stability was the issue for clients. She noted that they hated volunteer shifts being changed. The importance of time with clients was raised by one co-ordinator, who allowed for this in her schedule. Identifying families or individuals at risk was an important issue for a co-ordinator in a youth centre. He used all his contacts in a small local community to target children 'at risk'. A difficulty raised by one of the co-ordinators related to managing conflict between the desires or needs of the clients themselves and those of the client's family. Many coordinators were experiencing some issues in resolving the different demands of funding bodies, government regulations, volunteers, clients and their families for quality services.

\section{Discussion}

Four dimensions for the evaluation of quality were introduced in the introduction, the fixed versus the contextual dimension, the expert versus the experiential dimension, the existence of a single or multiple positions on quality and the significance of power relations.

The results suggest that clients' perceptions of quality were highly experiential and contextual with a strong awareness of their relative lack of power. For clients, the social experiences were even more important that the program provided. Signs of quality for clients were, warm personal relationships, feeling safe and accepted, reduced anxiety, increased confidence, greater pleasure in life, more contact in the community. Similarly in Waring's (1998) study of clients' experiences of receiving welfare handouts, positive experiences were associated with feeling supported and negative experiences were almost all associated with being feeling pur down by the agency. Such signs of quality in a client's social experience are not easily measurable. Psychological scales do exist to measure 
concepts such anxiety, life satisfaction, self-confidence but, as Gibson (1998) found such assessments are unlikely to be suitable for diverse and vulnerable clients.

There were strong similarities between the volunteers' and clients' views of a quality servic as experiential and contextual with volunteers also focussing on the personal aspects of their role. For volunteers, therefore, bureaucratic approaches to quality such as selection, training, detailed procedures and performance monitoring were not "the main game." However, there was some appreciation of the expert as knowledge and procedures were accepted and often valued by volunteers as long as they were seen as clearly contributing $\mathrm{tc}$ quality outcomes as they perceived them. Procedures were resented if they were seen as irrelevant red tape, insulting to the volunteers' competence or unnecessarily curtailing thei autonomy. Rural volunteers, in particular felt their context was not being taken into account (Onyx, et al, 2001).

Most coordinators appeared to have a mixed view of quality, combining aspects of the expert and the contextual, experiential approaches. So they tried both to follow prescriber procedures and also to fulfil the clients' and volunteers' expectations. They seemed to be engaged in a balancing act between the different quality expectations. Despite the difficult of managing the differing expectations, there were very few reports of feelings of conflict, apart from the concern of coordinators in the focus groups about the reactions of long-standing volunteers to new procedural requirements. Only one coordinator explicitly adopted the fixed, expert approach and she had replaced her management committee of clients, volunteers and community with a board of professionals. Coordinators did not seem to distinguish between legislative and funding body requirements. Only one coordinator raised concerns about the market model, pointing out that it was those services that were most needy that were least able to mount a successful submission. As Lyons (2001) argues, this competitive model privileges the large organisations, most of which are church sponsored. However, we have also found many organisations working collaboratively with other organisations (Onyx, et al., 2001) thus ignoring the demands for competition.

The data support the notion that there are multiple rather than a single position on the nature of quality. One example of a difference between volunteers and clients was on the issue of volunteer flexibility. Flexibility of work times was highly valued by volunteers. Clients, however, needed to develop trust, which takes time and consistency in personnel and procedures. Given the clients' aversion to change, the volunteers' right to vary their work times needs to be negotiated against the clients' need for consistency. Further, the demands for constant improvement in Quality Management require constant change, which contradict the clients' desire for consistency. Another example is that quality, as defined by policy and procedures, discourages physical contact. In contrast a number of clients and volunteers saw volunteering as essentially about a human connection and physical contact is, therefore, a highlight of a good voluntary service and could well be sees as a core indicator of quality.

The affect of power positioning on the assessment of quality was well illustrated by the issue of making complaints. Although almost all the client interviewed in this study said th: they felt able to make complaints about their current services, some would only do so with others and it must be remembered that as research participants these were people who were already willing to speak up. Volunteers and coordinators reported that methods such 
as suggestion boxes and surveys were not successful. Given the importance of personal relationships and feelings of safety by clients, it would be expected that clients would only make complaints when they feel personally safe with the personnel to whom they are complaining. Some coordinators made a point of developing trusting relationship with all clients but this may not always be feasible. Volunteers did not appear very conscious of clients' sense of powerlessness. There were, however, important ways in which volunteers empowered clients through encouraging new activities, increasing their confidence and linking them to the community.

A critical reference group approach (Wadsworth, 1997) takes the position that clients' views are paramount, but of course this needs accessible information, time for careful consideration and confidence by clients that their views are taken seriously. All coordinators had a strong commitment to client welfare and would put clients' needs before those of all others, including volunteers. They could generally be said to take a "critical reference group" approach to quality. But this was not necessarily the case; some were highly focused on clients needs but allowed others to determine what those needs were. The most strongly emancipatory was a feminist group in which all volunteers were clients and clients determined all the programs.

The stress of implementing the fixed, expert, singular quality procedures of new government requirements generally falls to the management committees, paid workers and volunteer coordinators so the possible contradictions arising from the differing understandings of quality are most likely to affect the volunteer coordinators, rather than volunteers or clients. It is reasonable that clients were not aware of the organisational concerns with policy and procedures, as they tend to be in the background in a well-run service. If the organisation of services deteriorated, clients could become more aware of the processes involved. Generally volunteers felt free to judge for themselves what was necessary and to complain about or just ignore what they considered to be unnecessary red tape.

Coordinators generally seemed to believe they could satisfy all parties. However, there are inherent contradictions. As Weber (1978) noted, the objectivity of procedures may objectify people and thereby alienate the very people the service is for. Informality was one way in which coordinators managed the contradictions. For example, formal assessment and review procedures, which might alienate many volunteers, are replaced by "having a chat", which can cover the same content but in a manner that can highlight the current context and a volunteer's personal experience. Similarly an open door policy can avoid the need for formal grievances to be lodged. However with increasing demands for formalised procedures such options may not be possible. The reality for most organisations is that they will experience a degree of stress trying to comply with different types of quality because they are subject to the requirements of the law and of funding bodies on the one hand and have a commitment to their clients on the other.

A first step in dealing with the tension is probably to recognise the multiple perspectives on quality. At present it appears that the debare is being silenced under the weight of bureaucratic requirements. The framework presented here aims to contribute to the widening of debate and the recognition of the diversity of positions. It is important not to get lost in distinctions between process, activity and outcome, when in practice they are hard to distinguish (Gibson, 1998). It is perhaps more important to make sure all voices 
about quality are heard. Equity is important but it is possible to have equity of access without having uniformity of service. The critical reference group are the least able to access information or to demand quality, as they perceive it, and considerable resources at needed to facilitate their participation. In particular it is necessary to treat with suspicion the claims to universality in terminology such as "quality assurance" and "TQM" (total quality management). When all perspectives cannot be sarisfied, it is ultimately a political decision as to whose interests prevail.

\section{References}

Cliff, N. and Kears, J A. (2003) Chapter 1, Ordinal Measurement in the Behavioural Sciences. Mahwah NJ: Lawrence Erlbaum.

Darcy, M. (2002) "Community management: How management discourse killed participation". Critical Quarterly, 44(4), 32-39.

Department of Health (2004). www.health.gov.au/internet/wcms/publishing.nsf/ Content/ageing-certification

Eisner, E. (1979). The Educational Imagination. New York:Macmillan.

Freeman, G. (2001). Best practice in volunteer involvement: What it is and how to achieve it. Australian Journal of Volunteering 6(2) 54-59.

George, V. \& Wilding P., (2002) Globalisation and Human Welfare Palgrave

Gibson, D. (1998). Aged Care: Old policies, new problems. Melbourne: Cambridge University Press.

Guba, E \& Lincoln, Y. (1986). Countenances of Fourth Generation Evaluation: Description, judgment and negotiation. Evaluation Studies Review 11, 70-87.

Leonard, R. and Hayward-Brown, H. (2002) "A qualitative analysis of experiences of women volunteers in human services". Third Sector Review, 8(2) 31-50.

Leonard, R., Onyx, J. and Hayward-Brown, H. (2004). Volunteer and coordinator perspectives on managing women volunteers. Non-Proft Management \& Leadership. 15(2) 205-219.

Lyons, M. (2001). The Third Sector: The contribution of non-proftt and cooperative enterprises in Australia. Sydney: Allen \& Unwin

McDonald, C and Marston, G (2002). Patterns of Governance: The Curious Case of Non-profit Community Services in Australia. Joumal of Social Policy and Administration.l 36 (4), 376-391.

McDonald, C. (1999). Internal control and accountability in non-profit human service organisations. Australian Joumal of Public Administration, 58(1): 11-22.

Mulgan, R. (2001). The accountability of community sector agencies: A comparative framework. Third Sector Review, 7(1) 89-105. 
Onyx, J., Leonard R., and Hayward-Brown H. (2001). "The Experience of Volunteers in the Provision of Human Services in NSW: A Regional Perspective", Australian Journal of Volunteering, 6(2), 128-144.

Postle, K. (2002). Working between the ideal and the reality: Ambiguities and tensions in care managers' work. British Journal of Social Work 32(3) 335-351

Rees, C. (2001). Worker responses to quality organisation: Discourse and materiality in organisational change. Work Employment and Society 15(4) 743-761

Smith, E. and Tyler, R. (1942). Appraising and Recording Student Progress. New York: Harper.

Wadsworth, Y. (1997) Everyday Evaluation on the Run. Allen \& Unwin: Sydney

Waring, M. (1998). Working in Community Services: Management and practice. Sydney: Allen \& Unwin.

Weber (1978) Economy and Society. (Translated by E Fischoff et al., Ed G. Roth and C Wittich) Berkeley: University of California 